\title{
KaLeP: A Holistic Case-based Action Learning Environment to Educate Successful Future Engineers
}

\author{
By Manuel Niever", Thilo Richter', Katharina Duehr", \\ Miriam Wilmsen ${ }^{+}$, Laura Lanz", Benjamin Walter ${ }^{\circ}$, \\ Albert Albers \& Carsten Hahn ${ }^{\star}$
}

The working environment of future university graduates is characterized by highly dynamic and complex product development processes. In addition to disciplinary competence, it is essential to build up methodical and social competence as well as to foster the elaboration and creativity potential of students. In order to meet industrial requirements the Karlsruhe Education Model for Product Development (KaLeP) was implemented. One element of this holistic education model is a design methods internship called ProVIL Product Development in a Virtual Idea Laboratory. The above mentioned integrated understanding of product development and the competences derived from it are successfully taught in the case-based action learning environment ProVIL. Additionally, the very important aspect of multidisciplinary product development in site-distributed teams is taken into account and generates an added value to the progression of the KaLeP. In this work the authors present the dimensions of competence which should be aimed for a holistic teaching approach for the interdisciplinary student courses in ProVIL. An example illustrates how a continuous alignment and the necessary adaption of competences of student project teams can be achieved within ProVIL.

Keywords: action learning, competency model, education model, product development.

\footnotetext{
*Doctoral Researcher, Institute of Product Engineering (IPEK) at Karlsruhe Institute of Technology (KIT), Germany.

${ }^{\dagger}$ Scientific Assistant, Institute of Product Engineering (IPEK) at Karlsruhe Institute of Technology (KIT), Germany.

${ }^{\star}$ Scientific Assistant, Institute of Product Engineering (IPEK) at Karlsruhe Institute of Technology (KIT), Germany.

${ }^{+}$Doctoral Researcher, Institute of Product Engineering (IPEK) at Karlsruhe Institute of Technology (KIT), Germany.

-Student, University of Applied Sciences Karlsruhe (HsKA), Germany.

Scientific Assistant, Institute of Product Engineering (IPEK) at Karlsruhe Institute of Technology (KIT), Germany.

'Head of Institute of Product Engineering, Karlsruhe Institute of Technology (KIT), Germany.

^Professor, University of Applied Sciences Karlsruhe (HsKA), Germany.
} 


\section{Introduction}

With increasing complexity of the development process from the idea to the product, the expectation of the industry towards an engineering graduate is constantly rising. Due to higher quality, time and cost pressures in the development environment, the integration of interdisciplinary knowledge is necessary to design new processes and methods. Furthermore, the engineer's work in the industrial and professional field is mostly characterized by teamwork nowadays. Therefore, pure professional expertise is unsatisfactory. In addition, methodological and social skills as well as creativity are required. In order to gain these competences, a holistic education model can meet the industries' expectations and foster the development of diverse competences which are vital for becoming a successful engineer.

This leads towards new approaches for university teaching which support the students in the development of broad professional competences. The KaLeP is a general education concept orientated at the real industrial development process and designed to promote competence in product development (Albers, Burkardt, \& Matthiesen, 2001). Next to the education of mechanical specialists, the KaLeP realizes the teaching of broad professional competences through a holistic approach including consecutive courses and individual events in different settings accompanied by intensive project work in student teams. It is mainly based on tripartite teaching in all areas starting with the mediation of knowledge in the first part, then extending it in the second and finally deepening it intensively in the third part (Albers, Burkardt, Robens, \& Deigendesch, 2009). The projects are design methods internships for students with the goal to consolidate theoretical knowledge and build up important skills, such as social abilities for teamwork and soft skills like creative potential. One example for these design methods internships is ProVIL, which is an interdisciplinary and inter-institutional education model as well.

\section{Literature Review}

\section{Competence Model and Learning Strategies}

The fact that a person must be able to master various types of competences in order to succeed at school, at work or simply in interacting with other people is not a recent realization, however. Since many years, pedagogues and educationalists have been studying the complex field of learning and have concluded that different approaches and strategies can lead to the acquisition of different kinds of desirable skills. In the following, some important models are illustrated which aim at structuring and classifying those methods and levels of teaching and learning with regard to the targeted outcomes, thus shaping the KaLeP model as it is today.

Learning Strategies. For the successful education of engineers, different learning and thinking strategies should be taken into account, considering that those strategies determine learning success as well as development of intellectual 
properties to a great extent.

While there are various ways of classifying such strategies in order to facilitate exchange between educators, Mandl and Friedrich (Mandl \& Friedrich, 1992) were able to identify a few approaches, which are most commonly used. One of them is the distinction in primary and support strategies. In this sense, primary strategies are defined as methods with direct influence on knowledge acquisition by actively improving the ability of grasping, memorizing, reproducing and applying knowledge in the same or a deviant context than originally taught. They are widely known as cognitive strategies and include a range of different methods, which describe exactly how information is processed (Mandl \& Friedrich, 1992; Mandl \& Friedrich, 2006):

- Elaboration strategies support the memorisation and reproduction of information by connecting it with already familiar knowledge, thus establishing multiple ways of accessing the information. Examples for elaboration strategies are posing questions, taking notes, creating images, etc.

- Organisation strategies describe the arrangement of information in order to form logic units of knowledge since it is easier to process chunks of data than detailed information. These strategies incorporate methods like summarising, classifying, etc.

- Knowledge-use strategies deal with methods regarding the transfer of information into another context than the original one. This can be exercised by leading discussions, writing essays, etc.

In comparison to these primary strategies, support strategies only have indirect influence on knowledge acquisition by affecting e.g. motivation, concentration or time management. Amongst others, they encompass the following strategies: (Mandl \& Friedrich, 1992; Mandl \& Friedrich 2006)

- Motivational and emotional strategies promote aspects like motivation, attention over time, endeavour, etc. These factors have a great effect on the successful application of primary strategies and are affected by e.g. interest in the learning objective, the desire to broaden one's own knowledge or beneficial surroundings.

- Cooperation strategies regulate the learning within a group, e. g. school classes or working groups. On the one hand, this enhances motivation because participants motivate each other. On the other hand, it adds value to cognitive processes since each person introduces new knowledge others can benefit from.

- Meta-cognitive strategies or control strategies are superior to cognitive strategies, yet only providing supporting functions regarding knowledge acquisition. They incorporate all methods aiming at self-reflection of one's own knowledge acquisition processes, including the act of planning, monitoring and evaluating. 
While the above explanations only show a very compressed characterisation of different learning strategies, Mandl and Friedrich explicitly state that such classification systems are not complete since there are still strategies and methods not included in the scheme. Furthermore, it sometimes can be very difficult or even impossible to exclusively assign a strategy to one single category (Mandl \& Friedrich, 1992).

Categorization of Knowledge. In order to apply these learning strategies, which have an active influence on knowledge acquisition; it is important to categorize the goals of teaching. A set of consistent definitions of abilities that students acquire through the teaching process will support the educators in designing syllabuses and exam papers that serve the targeted teaching goals. Therefore, Benjamin Bloom (1974) developed the Bloom's Taxonomy in 1948. It is a classification system which consists of six categories, each containing several subcategories (except the third category) arranged from low to high level of complexity and abstraction. By this means, it becomes clear that in order to perform high ranked abilities, it is necessary to master lower ranked abilities beforehand (Bloom, 1974).

The six main categories of Bloom's Taxonomy are the following:

1. Knowledge: It encompasses the act of remembering information and reproducing it in the same or a similar way that it was taught.

2. Comprehension: A student does not simply remember a specific information but is able to understand its meaning in order to modify or develop the information further.

3. Application: A student is able to identify a situation similar to known problems, select a suitable information or method and exercise the solution on his own.

4. Analysis: It describes the ability to break down the structure of information and identify relations and interactions between the elements.

5. Synthesis: A student can combine components of different information in order to form new information that did not exist before.

6. Evaluation: A student is able to assess information according to specific criteria, enabling him to form an opinion based on facts rather than expressing a subjective judgement (Bloom, 1974).

After several years, Lorin Anderson and David R. Krathwohl (Krathwohl, 2002) adjusted the original taxonomy as shown above, hence giving it the name Bloom's Revised Taxonomy. Since the category Knowledge encompasses not only the teaching goal (remembering and reproducing) but numerous types of information as well, it can be split up into the Knowledge Dimension, consisting of Factual, Conceptual, Procedural and Metacognitive Knowledge, and the Cognitive Process Dimension containing the six main categories of Bloom's original taxonomy (Anderson \& Krathwohl, 1974). In addition, the original categories were renamed and Synthesis and Evaluation were exchanged (Krathwohl, 2002).

Consequently, it is now possible to make statements about the quality of a course according to the diversity of tasks as well as to identify neglected teaching 
goals which should be included stronger into the syllabus (Krathwohl, 2002).

Education Models for University Teaching. The already named KaLeP is an example for a holistic education model for product engineers. It aims to train integrated product developers who have already been successfully educated in all relevant fields of competence. These competences are embedded in a so-called competence spider which includes the following aspects:

- Disciplinary competence (e. g. basic knowledge in mathematics, machine parts, foreign language)

- Methodological competence (e. g. development methods, FMEA, CAD)

- Social competence (e. g. communication and teamwork, presentation skills)

- Creative potential (e. g. creativity techniques, problem solving capability, courage for new solutions)

- Elaboration potential (e. g. focus on customer view, cost awareness, put theoretical knowledge into practice)

As mentioned beforehand, the model is divided into three parts. It starts with teaching the theoretical knowledge in lectures, followed by tutorials where the students apply the gained knowledge and the implementation of the knowledge in a workshop with a case-based project. Within these consecutives courses a product development-specific knowledge in systems, methods and processes is taught. The workshops are embedded in an industry-near development environment (Albers, Burkardt, \& Duser, 2006). This goes back to the benefits of the education method called Action Learning.

As a pedagogical method, Action Learning is based on its originators, Reginald W. Revans, assumption that learning has two major components: Programmed Knowledge and Questioning Insight (Revans, 1982).

Programmed knowledge is understood as all the expertise a person possesses whereas questioning insight describes one's ability to pose the right questions in order to solve new problems with uncertain outcomes, thus helping to identify required knowledge and to re-structure it to serve the purpose. Considering this, Revans (Revans, 1983; Hauser, 2012) set up the following equation:

$$
\mathrm{L}=\mathrm{P}+\mathrm{Q}
$$

It states that learning (L) can only be successful if both factors, programmed knowledge $(\mathrm{P})$ as well as questioning insight $(\mathrm{Q})$, are involved. However, especially in this day and age, in which surrounding conditions become more and more volatile and change is omnipresent it cannot be sufficient anymore to simply rely on knowledge from the past. The significance of $\mathrm{Q}$ rises as the need of adaption to previously unknown situations becomes greater (Revans, 1984). Therefore, in Revans opinion, conventional teaching methods in which an expert explains his special knowledge to his students are not adequate anymore (Revans, 1982). Instead, he asks for a practical learning environment, where students encounter and resolve problems, risk and uncertainty as they do in their everyday work. When practicing Action Learning, students form so-called learning 
communities in which they discuss arising problems at eye level. For this purpose, they meet on a regular basis and introduce each other to currently difficult situations. They tackle problems together by sharing opinions, proposing possible solutions, and putting them into practice. This approach is beneficial to each member of the learning community. From time to time everyone finds himself in the position of either giving or receiving advice and everyone can benefit from the advice given by other members of the group. While special expertise might still be necessary to some extent, the role of a tutor can be transferred onto the group because each member has different knowledge that he can share with the rest of the community (Revans, 1983; 1999).

Another advantage of seeking support among like-minded students is that their commitment is usually higher than it is the case with theoretical experts and tutors. While tutors are not involved in the same way future managers are and not responsible for the outcome of practical implementation of their theoretical knowledge, the members of the learning community are far more motivated to find appropriate answers because they might be in need of them at some point as well (Hauser, 2012; Revans, 1984).

In conclusion, one must mention that there is no predefined step-by-step procedure for carrying out Action Learning. It is an open concept on group learning and each learning community must figure out for itself how to learn and improve most effectively (Hauser, 2012).

\section{Live-Labs as Real-World Validation Environments}

Live-Labs are validation environments, which are used by design researchers to investigate design processes, methods and tools under realistic conditions in the context of product engineering. At the same time, they allow the design researcher a high controllability of boundary conditions (Albers, Bursac, Walter, Hahn, \& Schröder, 2016a). A common example for Live-Labs is innovation projects with companies and students where the main objective is to develop technical solutions for customers while using predefined project resources. Due to the real-world character of Live-Labs, it is possible to examine the suitability of design processes, methods and tools regarding their intended use within a real-world application (Walter, Albers, Benesch, \& Bursac, 2017a). Hereby, it is possible to increase the external validity of the validation results through the systematic design of the Live-Lab environment. Therefore, it is necessary to analyze the attributes of the real-world application of design processes, methods and tools in detail to decide how the attributes of the Live-Lab environment need to be designed. There are four different cases to decide on the value of the respective Live-Lab attribute, as simulation, variation, exploration and boundary condition check. In general, these four cases enable the design researcher to design the boundary conditions of the Live-Lab study in detail, thus increasing the external validity of the validation results (Albers, Walter, Wilmsen, \& Bursac, 2018).

In order to investigate the currently most relevant challenges of product engineering teams, the Live-Lab ProVIL - Product Engineering in a Virtual Idea Laboratory - was generated. Within ProVIL, mechanical engineering master 
students develop technical solutions for future customers in cooperation with industrial engineering and international management master students (Hahn et al., 2017). Furthermore, every ProVIL participant has a different specialization within their master courses. By this means, each team consists of future design engineers as well as test or automation engineers and business experts (Albers, Bursac, Heimicke, Walter, \& Reiß, 2017a). Thus, it is possible to examine the challenges of interdisciplinary collaboration within product engineering projects. Another important challenge of modern product engineering teams is the distributed collaboration, caused by the increasing globalization and internationalization of companies. To mirror this challenge within ProVIL, the students are working with different online tools, such as Jira for project management or SAP Innovation Management for evaluating product ideas and concept within the community (Walter, Albers, Heck, \& Bursac, 2016). Thereby, the Live-Lab ProVIL enables design researchers to investigate design processes, methods and tools for interdisciplinary and (partly) distributed product engineering teams. For example, in ProVIL 2017 two method variants of the scenario-technique for distributed product engineering teams were developed and successfully researched through an extensive Live-Lab study. Live-Labs thus contribute to the development and research of design processes, methods and tools for the PGE - Product Generation Engineering (Walter, Wilmsen, Albers, \& Bursac, 2017b). The approach of PGE "is understood as the development of products based on reference products (precursor or competitor products). The subsystems are either adapted to the new product generation by means of carryover or they are newly developed based on shape variation or principle variation" (Albers, Behrendt, Klingler, Reiß, \& Bursac, 2017b).

\section{Integrated Product Development}

The iPeM - integrated Product engineering Model is a unique metamodel for modelling product development in the context of the PGE (Albers, Reiß, Bursac, \& Richter, 2016b). It is based on a systems theory and represents a central element of the Karlsruhe School of Product Development (KaSPro). With iPeM, product development processes can be modelled holistically.

The iPeM is based on the elements of the triple based systems theory according to Ropohl (Ropohl, 1975) which describes product development with the following three interacting systems: the system of objectives, the system of actions and the system of objects [meaning "subject system" according to (Ropohl, 1979). He describes the connection between the system of objectives, the system of actions and the system of objects with a control loop.

Since this paper deals with holistic development in teams, the system of actions will be discussed in more detail below. It creates the system of objects on the basis of the system of objectives or further develops an existing system of objectives (Albers \& Braun, 2011). The system of actions is a socio-technical scheme consisting of structured activities, methods and processes. It also contains all resources necessary for the realization of a product development, e. g. developer, budget and equipment (Meboldt, 2009; Albers, Lohmeyer, \& Ebel, 
2011). In the course of the product engineering process, the system of actions can be expanded (e. g. new team members or equipment) or minimized (elimination of resources).

In the system of actions of the iPeM, different layers are modelled. The first levels describe the development of a product. One level is added for each subsequent product generation. The development of validation and action systems and strategy development form a separate level as well. This allows relationships between different products, product generations, validation and production systems. Additionally, corporate strategies can be mapped and resources and goals can be planned across multiple product generations (Albers, Reiß, Bursac, \& Richter, 2016b).

In order to be able to implement the activities of product development in the system of actions, iPeM applies the problem-solving method SPALTEN. In the first step of the SPALTEN process, a suitable problem-solving team is assembled for each situation. This is repeated between each further SPALTEN step (Braun, 2013).

Through the consideration of all activities in the product development process, their planning and implementation in the phase model, the mapping of the entire company process across the various levels and the company-wide consideration of three interacting systems, as well as the relationship of all elements mentioned, the iPeM supports the holistic development in the team. Above all, this applies to the modelling of the system of actions as a sociotechnical system since it supports the problem-solving team with concrete methods.

\section{Methodology}

The state of the art implicates that a holistic education model which is based on case-based action learning fosters the development of diverse competences for the education of future engineers. Within the KaLeP, Live-Labs are used to intensively deepen the students' expertise as well as develop competences in situations which require diverse and connected sets of competences. Especially in the Live-Lab ProVIL, the interdisciplinary and distributed teamwork with different disciplines is mediated. This contribution focuses on the research about the integration of different learning strategies and competence models in a holistic teaching model referring to the following research questions:

1. Which dimensions of competence should be aimed for a holistic teaching approach for the interdisciplinary student courses in ProVIL?

2. How could a continuous alignment and the necessary adaption of competences of the student project teams be achieved within ProVIL?

In order to answer these research questions, the authors initially analyzed which competence profile is required for successful future product engineers. For this purpose, both the state of the art and an interview with two professors from the 
fields of product development and innovation management were analyzed, thereby making it possible to determine the target competences of product engineers with a mechanical engineering and an economic focus. In particular, existing competence models of literature became a basis for creating characteristic competence profiles. In the next step, the different Live-Labs, especially ProVIL, were analyzed with regard to the competences imparted here. In several joint workshops with LiveLab experts the competences taught within ProVIL were evaluated by using the already mentioned competence models from literature. Finally, the target competences of future product engineers were compared with the competences imparted in ProVIL. Deviations between the target and actual competence profiles were determined. These deviations were carefully considered and it was evaluated to what extent it is necessary to expand the Live-Lab ProVIL. Further considerations concerned the question whether additional courses should be offered or whether this competence is already sufficiently covered by other courses of the master's program.

\section{Results}

Within ProVIL, the education models of the two courses for master students at the Karlsruhe Institute of Technology (KIT) and the University of Applied Sciences Karlsruhe (HsKA) were analyzed. The courses, which are integrated in the product development project, encompass the likewise named design method internship ProVIL for Mechanical Engineering students and the course called Innovation Process Coaching for International Management and Industrial Engineering students at the HsKA.

Both courses are based on the action learning approach, which means that students acquire knowledge by working on the development project with a defined project process. Additionally, there are three Kickoffs at the beginning of each project phase. During the Kickoffs, students learn about the theoretical background of the tasks, deliverables and goals of the next phase. Furthermore, there are some special training workshops for methods such as a creativity method workshop or a business model generation workshop to methodologically prepare the students for the upcoming tasks. In conclusion, the action learning approach got expanded with some theoretical training.

\section{Categorized Competence Model of ProVIL}

The research of the education models of these courses is based on the state of the art competence models and learning strategies. The action learning based knowledge transfer during the development process of generating new inventions in cooperation with an industrial partner fosters the different learning strategies. For example, the research activities the students perform in the analysis phase can be assigned to elaboration strategies because the students use their existing knowledge and reproduce new information through connecting it with the collected information from their research fields. Furthermore, the knowledge-use 
strategy is applied in activities in which the students use knowledge from market research and transfer the information into another context by using the scenario technique. Due to the real industrial challenge from the project partner company the students are eager to learn and apply new knowledge which represents motivational and emotional strategies.

In order to organize the taught knowledge, the different activities of the students in ProVIL are structured with the competences of the KaLeP competence spider and categorized by Bloom's Revised Taxonomy. The adjusted taxonomy enables the categorization of activities with suitable descriptions due to the renamed categories.

Because of the fact that ProVIL is one of the courses of the third stage of the KaLeP, the teaching focus lies in the implementation of already gained knowledge. Therefore, the disciplinary competences are implied as given.

In Figure 1 some selected key activities of the students during ProVIL and the corresponding competence category for the two courses are presented on basis of Bloom's Revised Taxonomy. These key activities are assigned to the teaching of methodological competence. The first example is the starting activity of an intensive market research towards the main research fields of the development challenge. The mechanical engineers participating in ProVIL conduct the tasks of market research and statistical analyzing. Therefore, their competence in these fields ranks in the fourth stage of analyzing. The students participating in Innovation Process Coaching who accompany in these tasks need to understand the methodological process they are running through.

Figure 1. Categorized competence model of ProVIL

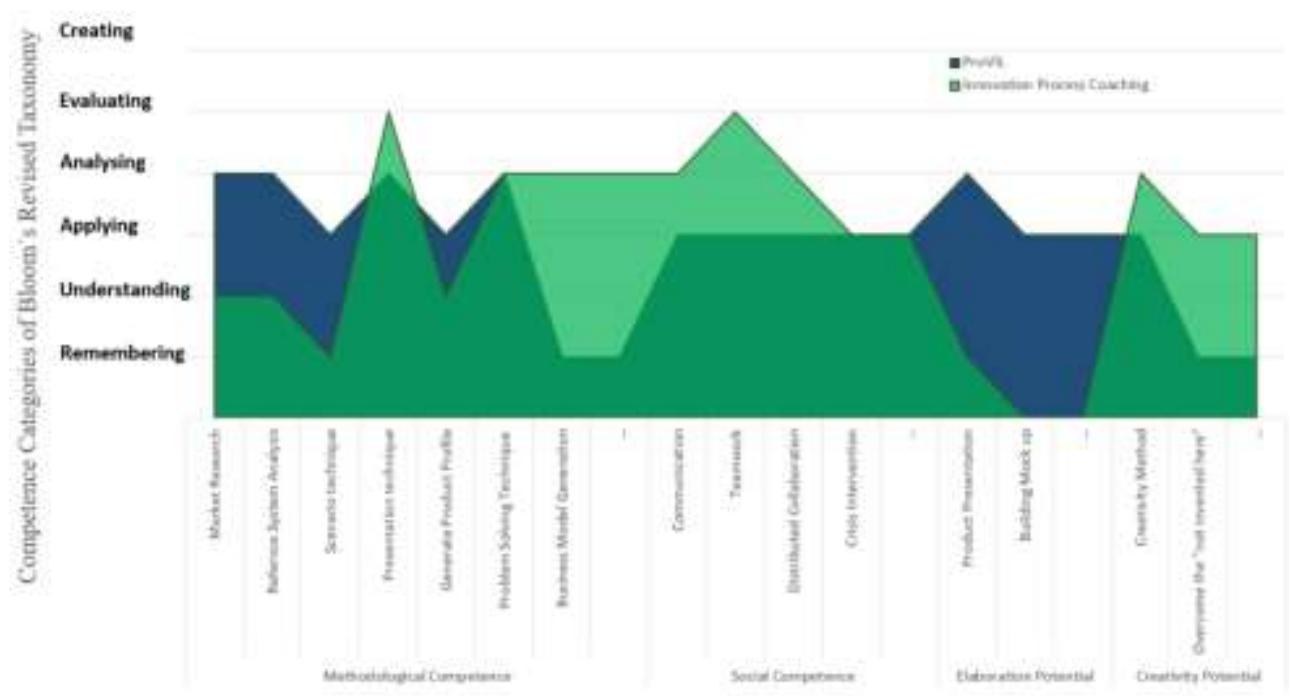

Another example of the assigned activities is the presentations of the students at milestones. During the development project, there are three milestones during which the students present their current deliverables to the project management as well as to the industrial project partner. Upfront, there are pre-milestones during which they get feedback on their presentation from the project management and their fellow students. In regard to the presentation competence, the ProVIL 
students apply their case-based knowledge about presentation techniques. Due to their task to challenge and assess the given presentations in a clear and structured way, the Innovation Process Coaching students acquire the competence to analyze and evaluate presentation techniques.

As a result of the interdisciplinary composition of the development teams, the students acquire social competences during the real product development process. Especially through the aspect of many virtual meetings, workshops and milestones, they learn how to communicate and collaborate in site-distributed teams. Due to the responsibility of the innovation coaches to moderate and organize the collaboration of the teams, they gain a high social competence.

\section{Education Model for successful interdisciplinary Collaboration}

As a Live Lab for distributed teams, ProVIL simulates, amongst others, the cooperation of project stakeholders from different specialist areas in a virtual space in the early phase of PGE. The students of the HsKA, working as Innovation Coaches in ProVIL, have an economic background. The product developers in ProVIL, however, study mechanical engineering.

In order to enable cooperation, a common language must be established. Figure 2 shows the characteristics of the competences of innovation coaches and product engineers before the start of ProVIL, based on analysis of the project years 2016 and 2017. On closer examination of the competences that can be acquired in different study programmes, it becomes clear that the students build up knowledge and competences in the specific subject areas but learn little interdisciplinary knowledge. Figure 2 displays the resulting competency-triangles of the participants identified before the start of ProVIL. Both stakeholders have profound professional competences in the focus of their subject-specific study programmes up to the competence category Creating of the Bloom's revised Taxonomy.

Figure 2. Competence-triangles of Master Students without ProVIL

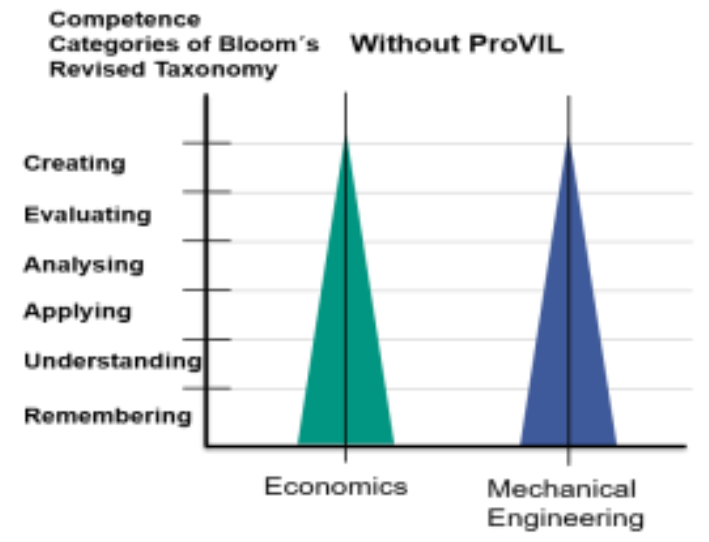

However, successful cooperation can only be guaranteed with a common language, e. g. an overlapping field of competence must be sought. In the course of the project, further competences (cf. Figure 1) are built up through sole participation in the project and the associated mandatory events such as kick-offs 
and milestones. The development of these additional competences leads to the ProVIL participants reaching the level of "understanding" by overlapping their fields of competence, thus facilitating cooperation (cf. 3). Additional targeted training during the process, such as the Pitch 2.0 workshop, in which ProVIL participants learn to present their ideas to the customer within a very short time to convince the customer of their ideas, maximise the range of the competence field additionally. A more effective cooperation can be achieved by expanding the competence-triangles of the participants and forming the competence overlap on a higher level of the competence fields according to Bloom's revised Taxonomy.

Figure 3. Competence-Triangles of Master Students with ProVIL (Left) and with Specific Training in ProVIL (Right)

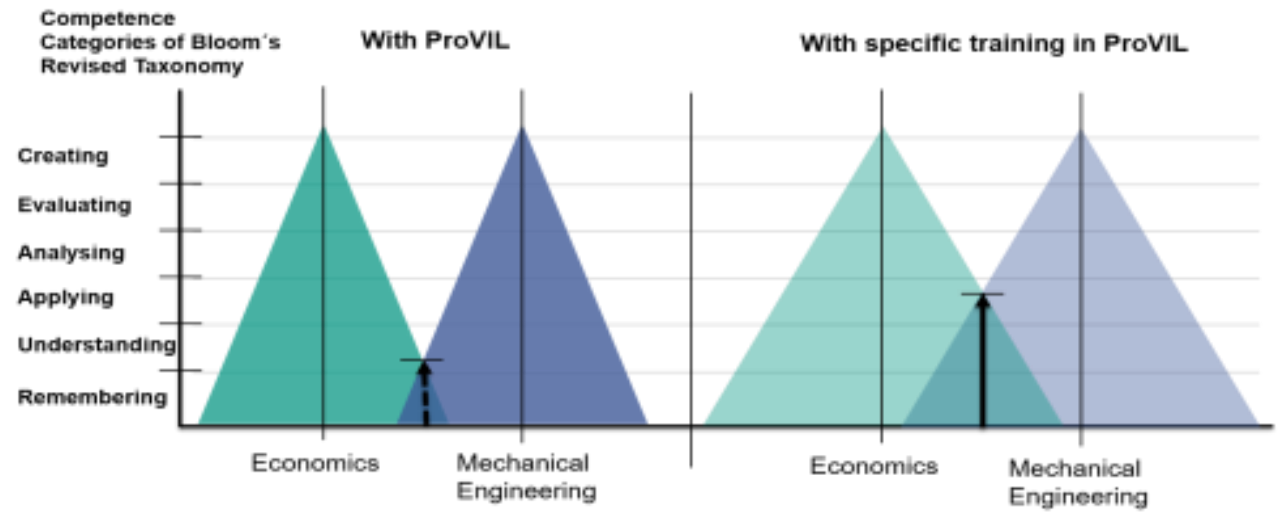

\section{Conclusion and Outlook}

The holistic case-based action learning environment KaLeP shows an integrated teaching model to educate successful future engineers. The most important aspect is the extended competence model with methodological, social competences as well as elaboration and creative potential next to the disciplinary competence of an engineer. This integrated understanding of necessary product engineering competences is taught in regard to established learning strategies. On the basis of a structured categorization of activities and with it the taught competences, the case-based action learning course with additional trainings, called ProVIL, has been build up. It shows that the education model is very successful in teaching competences for interdisciplinary collaboration. Especially for future distributed collaboration and virtual workspaces, the importance of social competences of an engineer increases significantly.

Regarding the impressive outcomes of the ProVIL projects in 2016 and 2017, during which the students developed mock ups and physical prototypes of their inventions, the added value of the interdisciplinary project teams with mechanical engineers as product developer and economists as innovation coaches was exposed. The implemented product development process enabled the student teams to fit their complementary competences and efficiently generate inventions with high innovation potential. 
Due to targeted analysis pointing out the lack of competences of participants, training courses could be used in order to maximize the competence triangles, thus enabling cooperation at higher levels according to Bloom. With further research on time-scalable and stakeholder specific training courses with a modular set up, the aim is to create complete a holistic competence model for successful collaboration within interdisciplinary product engineering teams.

\section{References}

Albers, A., \& Braun, A. (2011). A generalized framework to compass and to support complex product engineering processes. International Journal of Product Development, 15(1/3), 6-25.

Albers, A., Behrendt, M., Klingler, S., Reiß, N., \& Bursac, N. (2017b). Agile product engineering through continuous validation in PGE-Product Generation Engineering. Design Science, 3.

Albers, A., Burkardt, N., \& Matthiesen, S. (2001). New education concepts for the training of creative engineers-The Karlsruhe education model for industrial product development-KaLeP. In Proceeding of the 23rd SEED Annual Design Conference and 8th National Conference on Product Design Education, Derby, United Kingdom.

Albers, A., Burkardt, N., Robens, G., \& Deigendesch, T. (2009). Das Karlsruher Lehrmodell für Produktentwicklung (KaLeP) als Beispiel zur ganzheitlichen Integration von Projektarbeit in die universitäre Lehre [The Karlsruhe Education Model for Product Engineering (KaLeP) as an example for the holistic integration of project work into university teaching].

Albers, A., Burkardt, N., \& Duser, T. (2006). Competence-profile oriented education with the Karlsruhe Education Model for Product Development (KaLeP). World Transactions on Engineering and Technology Education, 5(2), 271.

Albers, A., Bursac, N., Heimicke, J., Walter, B. \& Reiß, N. (2017a). 20 years of cocreation using case based learning. An integrated approach for teaching innovation and research in Product Generation Engineering. In Auer, M.E., Guralnick, D. \& Uhomoibhi, J. (Eds.), Proceedings of the 20th ICL Conference, Springer. https://doi. org/10.1007/978-3-319-73204-6_69.

Albers, A., Bursac, N., Walter, B., Hahn, C. \& Schröder, J. (2016a). ProVIL Produktentwicklung im virtuellen Ideenlabor [ProVIL - Product Development in a Virtual Idea Laboratory]. In Entwerfen, Entwickeln, Erleben Werkzeuge und Methoden in Produktionsentwicklung und Design, pp. 185-198. Dresden. ISBN: 978-3-95908-062-0.

Albers, A., Lohmeyer, Q., \& Ebel, B. (2011). Dimensions of objectives in interdisciplinary product development projects. In 18th International Conference on Engineering Design ICED 11, pp. 256-265. Copenhagen, Denmark,.

Albers, A., Reiß, N., Bursac, N. \& Richter, T. (2016b). iPeM - Integrated Product Engineering Model in Context of Product Generation Engineering. Procedia CIRP, 50, 100-105.

Albers, A., Walter, B., Wilmsen, M., \& Bursac, N. (2018). Live-Labs as Real-World Validation Environments for Design Methods. In DS92: Proceedings of the DESIGN 2018 15th International Design Conference 2018, pp.13-24.

Anderson, L. W., \& Krathwohl, D. R. (Eds.). (1974). A Taxonomy for Learning, Teaching, and Assessing. A Revision of Bloom's Taxonomy of Educational Objectives. Pearson. 
Braun, A. (2013). Modellbasierte Unterstützung der Produktentwicklung - Potentiale der Modellierung von Produktentstehungsprozessen am Beispiel des integrierten Produktentstehungsmodells (iPeM).[Model-based support of product development Potentials of modeling product development processes using the integrated product development model (iPeM) as an example] Research Reports IPEK.

Bloom, B. S. (Ed.). (1974). Taxonomie von Lernzielen im kognitiven Bereich. [Taxonomy of learning objectives in the cognitive field]. Weinheim and Basel: Beltz Verlag.

Hauser, B. (2012). Action Learning. Workbook mit Praxistipps, Anleitungen und Hintergrundwissen für Trainer, Berater und Facilitators [Action learning. Workbook with practical tips, instructions and background knowledge for trainers, consultants and facilitators]. Bonn: managerSeminare Verlags $\mathrm{GmbH}$.

Hahn, C., Albers, A., Stöckner, M., Niever, M., Walter, B., Kerres, R., \& Bursac, N. (2017). Innovation Coaching in Foresight Processes for Distributed Product Development. In CERC 2017 Proceedings, ISSN: 2220 - 4164.

Krathwohl, D. S. (2002). A Revision of Bloom's Taxonomy: An Overview. In Theory into Practice, 41(4). Ohio State University.

Mandl, H., \& Friedrich, H. F. (Eds.) (1992). Lern- und Denkstrategien. Analyse und Intervention [Learning and thinking strategies. Analysis and intervention]. Göttingen: Hogrefe Verlag für Psychologie.

Mandl, H., \& Friedrich, H. F. (Eds.) (2006). Handbuch Lernstrategien [Manual Learning Strategies]. Göttingen: Hogrefe Verlag.

Meboldt, M. (2009). Mentale und formale Modellbildung in der Produktentstehung - als Beitrag zum integrierten Produktentstehungs-Modell (iPeM) [Mental and formal modeling in product development - as a contribution to the integrated product development model (iPeM)]. Research Reports IPEK.

Revans, R.W. (1982). What is Action Learning. Journal of Management Development, 1(3), 64-75.

Revans, R. W. (1983). Action Learning: Its Origin and Nature. In Pedler, M. (Ed.) 2011. Action Learning in Practice, pp. 5-14. Surrey: Gower Publishing Ltd.

Revans, R. W. (1984). The Sequence of Managerial Achievement. Bradford: MCB University Press.

Revans, R. W. (1999). Action Learning: Wesen und Voraussetzungen [Action Learning: Essence and Prerequisites]. In Donnenberg, O. (Ed.), Action Learning. Ein Handbuch, pp. 28-43.Stuttgart: Klett-Cotta.

Ropohl, G. (1975). Einleitung in die Systemtechnik [Introduction to systems technology]. München Wien: Carl Hanser Verlag.

Ropohl, G. (1979). Eine Systemtheorie der Technik: zur Grundlegung der Allgemeinen Technologie [A system theory of technology: the foundation of general technology]. Hanser Verlag.

Walter, B., Albers, A., Benesch, G., \& Bursac, N. (2017a). ProVIL-Produktentwicklung im virtuellen Ideenlabor: Anwendungs- und Implementierungsmodell eines LiveLabs [ProVIL - Product Development in a Virtual Idea Laboratory: application and implementation model of a live lab]. In 4th Stuttgarter Symposium for Product Development 2017 (SSP), vol. 29.

Walter, B., Albers, A., Heck, M., \& Bursac, N. (2016). ProVIL - Produktentwicklung im virtuellen Ideenlabor: Anpassung einer kollaborativen Innovationsplattform zur Nutzung eines communityorientierten Innovationsprozesses [ProVIL - Product Development in a Virtual Idea Laboratory: Adaptation of a collaborative innovation platform to use a community-oriented innovation process]. In Proceedings 12. Symposium für Vorausschau und Technologieplanung 2016 (SVT 2016). 
Walter, B., Wilmsen, M., Albers, A. \& Bursac, N. (2017b). Zukunftsmanagement in Zeiten der Digitalisierung: Die Szenario-Technik als Innovationsmethode in der standortverteilten Produktentwicklung. [Future management in times of digitalization: Scenario technology as an innovation method in distributed product development] In Proceedings 12. Symposium für Vorausschau und Technologieplanung 2017. SVT, Berlin. 
